\title{
Perchlorate: Status and Overview of New Remedial Technologies
}

\author{
Katarzyna H. Kucharzyk, Terence Soule, \\ Andrzej, J.Paszczynski and Thomas F. Hess \\ University of Idaho \\ USA
}

\section{Introduction}

The reason for an increasing interest in perchlorate pollution includes recent advances in both analytical chemistry and better understanding of perchlorate's health impacts. The advances and developments of chemical methods have allowed detection of concentrations at low part-per-billion (microgram per liter $[\mu \mathrm{g} / \mathrm{L}]$ (Urbansky, 2000), and the toxicological research has suggested that such concentrations may be a potential risk for developing fetuses and infants (USEPA, 2002; Kucharzyk et al., 2010). Perchlorate inhibits iodide uptake by the thyroid causing disruption in normal thyroid function, which can lead to a number of serious health problems, especially pertaining to early neurological development (Blount et al., 2006).

There have been several high-profile cases of perchlorate contamination of surface waters and drinking water supplies in major metropolitan areas (Gullick et al., 2001) and the parties such as U.S. Department of Defense (DoD) responsible for the events had to quickly respond to the regulatory and public demand to prevent further exposures and clean up contaminated sites (Stroo et al., 2009). In January 2009, the EPA issued a heath advisory to assist state and local officials in addressing local contamination of perchlorate in drinking water. The interim health advisory level of 15 micrograms per liter (mg/L), or ppb, is based on the reference dose recommended by the National Research Council (NRC) of the National Academy of Sciences (NAS) (Kucharzyk et al., 2009).

The most recent technologies for remediation of perchlorate in groundwater are in the group of phytobioremediation, in situ bioremediation with the application of the Genetic Algorithms (GAs). More detailed descriptions of the technologies listed, along with the discussion of their scientific basis, current status and specific advantages and limitations are provided in this chapter.

\section{Perchlorate background}

\subsection{Properties and health effects}

Perchlorate is widely known to be a poor complexing agent and is used extensively as a counter anion in studies of metal cation chemistry, especially in non-aqueous solution (Urbansky, 2000). Its low association with cations is responsible for the extremely high 
solubilities of perchlorate salts in aqueous and non aqueous media. The predominant route of perchlorate exposure of humans (and animals) is via drinking of contaminated water and ingestion of contaminated foods like milk (Kirk et al., 2005) and vegetables (Jackson et al., 2005). Perchlorate is known to disrupt the uptake of iodine in the thyroid, potentially affecting thyroid function. A key concern is that, if sufficiently severe, impaired thyroid function in pregnant women can impair brain development in fetuses and infants (Urbansky, 2000). Because of the complex anatomy of the thyroid follicle, all of the locations where perchlorate inhibition is exerted remain to be established. One site of this inhibition is the sodium-iodide symporter, a membrane protein located on the basolateral side of the follicular cell, adjacent to the capillaries supplying blood to the thyroid (Urbansky, 2002; National Research Council, 2005). The competitive inhibition of iodide uptake is the only direct perchlorate effect on the thyroid, leading to a reversible chemical induced iodine deficiency. Alteration of hormones (T4, T3, and TSH) is considered to be the first observed effect of perchlorate exposure. Since perchlorate competitively inhibits iodine uptake in the thyroid it alters the levels of thyroid hormone, and during pregnancy even minute disruptions of thyroid hormone levels can have serious effects on a developing fetus. These effects can lead to a loss of hearing, deficiency in speech and motor skills, lowered IQ, and even mental retardation in infants and young children (EWG, 2007).

\subsection{Uses}

Perchlorate came into prominence as a pollutant in the late 1990s, and it has remained as an important issue for debate during the last decade. Along with the controversy, perchlorate contamination has also attracted an enormous amount of public interest (USEPA, 2002). In the early 1800s perchlorate became an alternative to the potassium nitrate containing black powder that had been used in fireworks until then. In the 1940s perchlorates became increasingly important as a component in propellants and explosives and still the main applications of perchlorate are in the explosives and chemical industries (Sellers et al., 2007). An important advantage of the oxidizer ammonium perchlorate over nitroglycerin as an additive to explosive is that is easy to use and can be handled relatively safely (Cunniff, 2006). Specific uses of the various perchlorate salts include: as a solid rocket fuel oxidizer, in flares and pyrotechnics, in explosives, and in chemical processes as a precursor to potassium and ammonium perchlorate (USEPA, 2002). Perchlorate salts are also used on a large scale as a component of air bag inflators and in small-scale laboratory applications as ionic strength adjustors or non-complexing counterions. In cotton production sodium chlorate is used as a defoliant and as a non-contact herbicide in other crops like sunflowers, rice, safflower, and sorghum (Kegley et al., 2008).

\subsection{Sources of perchlorate}

In nature, perchlorate may originate from two natural sources: soils and arid climates derived from ancient marine seabeds, and potentially, conditions during lightning storms. The main and largest known perchlorate source lies in Chile in Atacama Desert, where perchlorate is extracted from deposits of nitrate ores or brines. Other deposits are located in Death Valley, the high plains in Texas and New Mexico (Rajagopalan et al., 2006) , and the Bolivian playas (Orris et al., 2003), i.e. perchlorate deposits generally occur in very arid regions (Rao et al., 2007). Recently, high levels of perchlorate were reported on Mars (Hecht et al., 2009). This founding is rather exciting since perchlorate could be used as a support for life on Mars as a potential electron acceptor. The mechanism of how naturally occurring 
perchlorate is generated is not known or well investigated. Researchers suppose that perchlorate can be generated photochemically in the atmosphere or on chloride-coated mineral surfaces by ozone oxidation of chloride and by electrical discharge. The isotopic signature of perchlorate in arid regions points to a stratospheric origin of the compound (Jackson et al., 2006).

Anthropogenic sources of perchlorate are mainly associated with the manufactures of perchlorate or its use in defense-related operations such as rocket manufacture or munitions use or demolition (Cox, 2009). Perchlorate is principally a synthetic compound and its salts have a broad range of different industrial applications ranging from pyrotechnics to lubricating oils (Motzer, 2001). Its presence in the environment predominantly results from historical discharge of unregulated manufacturing waste streams, leaching from disposal ponds, and from the periodic servicing of military inventories (Urbansky, 2000; Urbansky, 20002). Specific uses of the various perchlorate salts include: as a solid rocket fuel oxidizer, in flares and pyrotechnics, in explosives, and in chemical processes as a precursor to potassium and ammonium perchlorate (USEPA, 2002). Perchlorate salts are also used on a large scale as a component of air bag inflators and in small-scale laboratory applications as ionic strength adjustors or non-complexing counterions. Sodium chlorate is produced predominantly electrochemically by electrolysis and can contain significant amounts of perchlorate as a contaminant, thus they significantly contribute to the total perchlorate load in the environments (Aziz \& Hatzinger, 2009).

\subsection{Biodegradation}

It has been known that microorganisms can reduce oxyanions of chlorine such as chlorate $\left(\mathrm{ClO}_{3}{ }^{-}\right)$and perchlorate $\left(\mathrm{ClO}_{4}^{-}\right)$[(per)chlorate] under anaerobic conditions. The high reduction potential of (per)chlorate $\left(\mathrm{ClO}_{4}^{-} / \mathrm{Cl}-E_{o}=1.287 \mathrm{~V} ; \mathrm{ClO}_{3}^{-} / \mathrm{Cl}^{-} E_{o}=1.03 \mathrm{~V}\right)$ makes them ideal electron acceptors for microbial metabolism (Coates et al., 2000). Early studies indicated that unknown soil microorganisms rapidly reduced chlorate that was applied as herbicide for thistle control and the application of this reductive metabolism was later proposed for the measurement of sewage and wastewater biological oxygen demand (Bryan, 1966). Initially it was thought that chlorate reduction was mediated by nitraterespiring microorganisms in the environment with chlorate uptake and reduction simply being a competitive reaction for the nitrate reductase system of these bacteria (de Groot \& Stouthamer, 1969). This was supported by the fact that many nitrate-reducing microorganisms in pure culture were also capable of reducing (per)chlorate (Roland et al, 1994). Furthermore, early studies demonstrated that membrane-bound respiratory nitrate reductases and assimilatory nitrate reductases could alternatively reduce chlorate (Steward, 1988) and presumably perchlorate.

In the past decade understanding of the biological perchlorate reduction progressed dramatically due to the development of the genetic analysis that offer tools for detecting and monitoring dissimilatory perchlorate-reducing bacteria for bioremediative purposes (Achenbach et al., 2006). The perchlorate reduction pathway consists of two central enzymes: perchlorate reductase and chlorite dismutase. The first enzymatic step of the pathway, the reduction of perchlorate and chlorate to chlorite, is performed by (per)chlorate reductase (Fig.1).The chlorite formed from this reduction is cytotoxic and requires immediate detoxification which is catalyzed by chlorite dismutase converting chlorite to chloride and oxygen (Wolternik, 2005).The generation of oxygen makes anaerobic (per)chlorate reduction unique when compared to other anaerobic respiratory processes. 
This aspect of (per) chlorate reduction has been of special interest because of its potential to introduce oxygen to anoxic sites to aide subsequent bioremediation strategies (Achenbach et al., 2006).

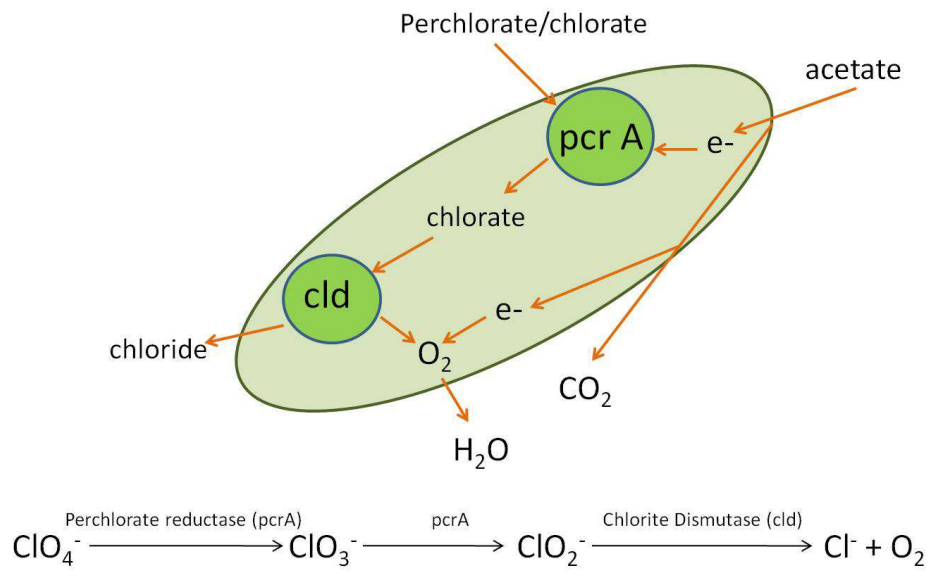

Fig. 1. Perchlorate reduction pathway. The reactions are catalyzed by perchlorate reductase (pcrA) that reduces perchlorate to chlorite and chlorite dismutase (cld) that converts toxic chlorite to chloride and oxygen (Adapted from Ederer et al., 2011).

\section{Emerging technologies}

\subsection{In situ perchlorate bioremediation with the application of evolutionary computation.}

\subsubsection{Genetic Algorithm outline}

Artificial intelligence (AI), such as Genetic Algorithms (GA), covers a wide range of techniques and tools that facilitate decision making and have often been found to be as powerful and effective as gradient search methods in many engineering applications (Schugerl, 2001). Genetic algorithms (GAs) (Holland, 1975) are search and optimization methods based upon the biological principal of evolution through natural selection and mimics biological evolution as a problem-solving strategy. GA tends to thrive in an environment in which there is a very large set of candidate solutions. Inspired by the Darwinian principle of evolution through natural selection, GA borrows part of the vocabulary from biology. Potential solutions to a problem (optimization trials) are conceptually considered to be individuals containing a chromosome encoding the details of the proposed solutions (Reeves, 1993). Such a chromosome consists of genes representing the system variables that are alleles of those genes. GA simultaneously operates on a collection of such solutions, called a population. Each candidate is evaluated accordingly to the fitness function that is quantitatively estimated (Goldberg, 1989).

Initially, the first generation of potential solutions is typically created at random. A new generation of solutions is created by selecting solutions from the old generation with a probability that is proportional to their fitness value (Vandecastelle, 2006). The selected individuals are called parents. After crossover and mutation are applied, these parents result in children that will make up the next generation of solutions (Fig.2). Crossover is a 
process that typically occurs with a high probability and in which pieces of chromosome are exchanged between pairs of parents.

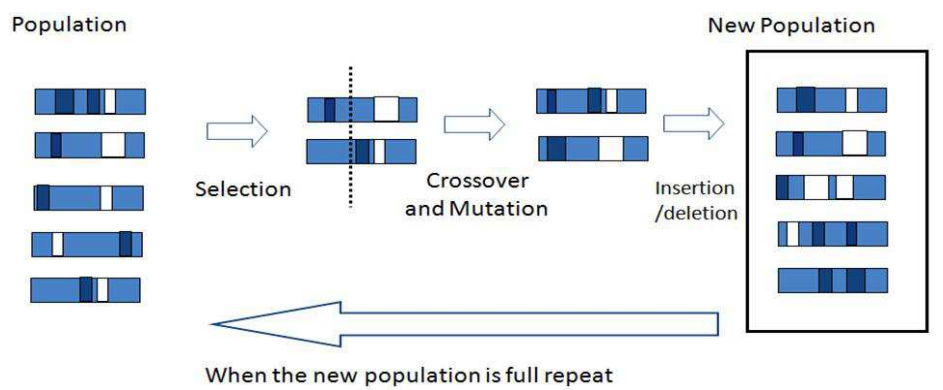

Fig. 2. Schematic outline of the operation of a Genetic Algorithm. (T. Soule, University of Idaho, personal communication)

During the process of mutation, each gene has a typically low probability of changing in allele value. The fitness value for the created generation is then evaluated, after which the process of selection, crossover, and mutation is repeated. The whole cycle is repeated until an acceptable solution is obtained or until experimental resources run out (Vandecastelle, 2006). This is best summarized with pseudocode, as shown below:

begin

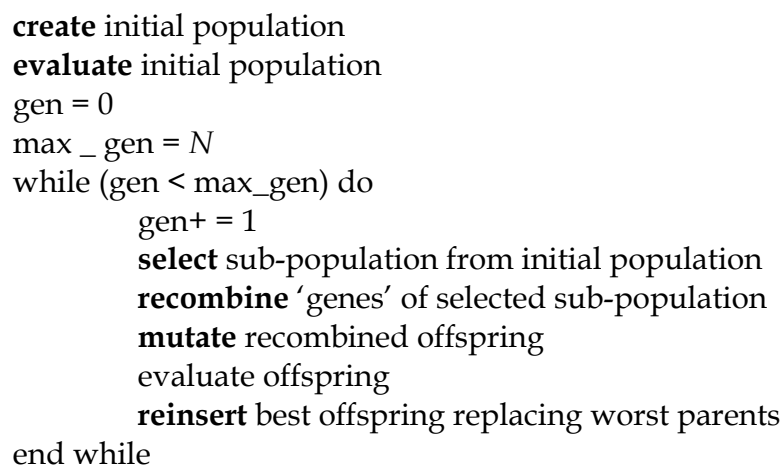

Genetic algorithms can cope with multiple interacting variables, operate under considerable levels of noise, and do not require an intricate understanding of the internal dynamics of a system that is to be optimized.

\subsubsection{Ecosystem manipulation}

Stochastical approaches, using GAs, have proven to be extremely suitable for optimization problems regarding many variables, such as fermentation media development (WeusterBotz \& Wandrey, 1995; Weuster-Botz et al., 1995) or in the progress of growth optimization considering the process parameters (Muffler \& Ulber, 2004). GAs have been successfully employed to search for the best subset from a large set of microbial isolates that can perform a variety of processes (Vandecasteele et al., 2004). The processes optimized include biomass production, biomass minimization, and xenobiotic compound degradation. The most recent studies are experimental multi-objective medium optimizations using a GA supported by 
hybrid Genetic Algorithm Artificial Neural Network (GA-ANN) (Franco Lara et al., 2006), optimization of exo-polysaccharide production by hybrid methodology comprising PlackettBurman design, ANN and GA (Desai et al., 2006), optimization of $\delta$-endotoxin production by Response Surface Methodology (RSM) and ANN (Moreira et al., 2007), modeling and optimization of fermentation factors for alkaline protease production using a feed-forward neural network and GA (Rao et al., 2007), optimization of fermentation media using neural network and genetic algorithm (Nagata and Chu, 2003), optimization of biodegradation of naphthalene by an isolated microorganism by response surface methodology (Martin \& Sivagurunathan, 2003), and tryptophan-5-halogenase activity assay formulation for enzyme activity optimization (Muffler et al., 2007).

A GA can be used to manipulate microbial ecosystem factors to obtain a desirable functional behavior. There are two ways being used to date. In the first approach, efficient mixed cultures can be designed by determining which isolated strains to combine for optimal functional performance (Jarvis \& Goodacre, 2005; Vandecasteele, 2004). Here, when designed and constructed appropriately, artificial microbial ecosystems exhibit complex behaviors that are observed in a variety of large-scale ecological systems (Kambam et al., 2008), and perform functions that are difficult or even impossible for individual strains or species (Brenner et al., 2008). These attractive traits rely on two organizing features: communicating with one another and the division of labor. By trading metabolites or by exchanging dedicated molecular signals, each population or individual responds to the presence of others in the consortium (Keller and Surette, 2006). This improves the overall output of the consortium that relies on a combination of tasks performed by a constituent individual or sub-populations (Brenner et al., 2008). If the components of an artificial microbial ecosystem are manipulated, the consequence of altering system complexity can be further explored.

It is possible to use a genetic algorithm to manipulate environmental conditions and drive an already existing ecosystem in a desired direction, e.g. maximized degradation rate (Kucharzyk et al., 2010). Certain environmental conditions can influence and cause shifts in ecosystem dynamics (Vandecastelle et al., 2004). Most applications using microbial consortia are in the field of industrial fermentation, where medium compositions are manipulated to maximize production of various chemicals (Bapat \& Wangikar, 2004; Etschmann et al., 2004; Fang et al., 2003; Patil et al., 2002; Weuster-Botz et al., 1995; Weuster-Botz et al., 1996). Similar attempts have been made to optimize medium conditions for oil degradation by a pure culture (Li et al., 2004) and for the growth of insect cells (Martin \& Sivagurunathan, 2003). An approach based on changing environmental conditions would start with identifying a set of conditions that influence ecosystem dynamics and that can be manipulated experimentally. Such conditions taken under consideration may include chemical and physical factors such as temperature, $\mathrm{pH}$, salinity, light treatment, and mixing. They could also include concentrations of electron donors, electron acceptors, and other chemicals (Vandecastelle et al., 2004).

\subsubsection{Genetic algorithm application to optimization of in situ perchlorate biodegradation}

Today, a wide variety of in situ biological treatment approaches are available to remediate perchlorate from ground and surface waters and soil, and remediation tools and techniques are available from a collection of technology vendors and environmental consultants (Ooi \& Tan, 2003). Biological ex situ treatment systems for perchlorate, as well as the isolation and 
characterization of numerous pure cultures of perchlorate-degrading bacteria from natural environments, has prompted significant research concerning the potential for in situ perchlorate treatment through electron donor amendment to soils and groundwater (Aziz \& Hatzinger, 2009). Because of its unique chemical stability under environmental conditions and its high solubility (Urbansky, 2002), microbial reduction of perchlorate was identified as the most feasible method of remediation of contaminated environments. The presented technology avoids the production of hazardous waste streams that require further treatment or disposal and addresses the need to develop in situ approaches for the remediation of perchlorate contamination of groundwater.

The overall goal of the in situ perchlorate bioremediation with the GA application is to engineer natural subsurface microbial communities (aquifer biofilms), to give them the ability to degrade (reduce) perchlorate, even in the presence of oxygen and without the addition of genetically engineered microorganisms (GMOs) to the environment. This approach is called "engineered intrinsic bioremediation." In the search for efficiently degrading mixed microbial cultures two approaches can be implemented. The first approach uses a GA to manipulate environmental conditions and drives an existing ecosystem in a desired direction, and the second approach uses a different GA to design efficient mixed microbial consortia by determining which isolated strains to combine for optimal functional performance. For that purpose several members of the (per)chlorate strain collection identified and selected as the most efficient in the perchlorate degradation process can be candidates for optimization (Table 1).

\begin{tabular}{lll}
\hline NAME & ATTCC / DSMZ & CR/PR* \\
\hline Pseudomonas chloritidismutans & ATCC \# BAA-775 & CR \\
Ideonella dechloratans & ATCC \# 51718 & CR \\
Dechlorosoma sp. KJ & ATCC \# BAA-592 & PR \\
Dechloromonas agitata & ATCC \# 700666 & PR \\
Dechlorosoma suillum & ATCC \# BAA-33 / DSMZ 13638 & PR \\
Azosypyra oryzae & DSMZ 1199 & PR \\
Dechloromonas hortensis & MA-1 DSM 15637 & PR \\
Dechloromonas sp. Miss R & Courtesy of J. Coates lab & PR \\
Dechloromonas denitrificans & ATCC BAA-841, CIP 109443 & CR,PR \\
Rhodobacter capsulatus & DSMZ 155 & CR,PR \\
\hline
\end{tabular}

Table 1. Examples of known perchlorate- and chlorate-degrading bacteria, used in the GA optimization experiment. *Perchlorate reducers are indicated as PR, chlorate as CR.

In the first part of the project a GA was used as an alternative method for directing and artificially defining a set of environmental conditions for naturally occurring microbial consortia and pure cultures to achieve maximum rates of perchlorate degradation. Samples collected from several areas contaminated with perchlorate were used along with pure cultures of perchlorate reducing microorganisms. The initial population (the algorithm's equivalent of a chromosome) was generated at random; a subunit of the bit string (the algorithm's equivalent of gene) gives the value of one parameter. Each experiment was performed in four replicates and a complete chromosome was composed of 36 bits, consisting of 9 medium components of 4 bit each (Table 2). 


\begin{tabular}{ll}
\hline & GA configuration \\
\hline Variables & 9 \\
Population size & 11 (single strains); 12 (consortia) \\
Generation gap & 1 \\
Selection probability & 0.5 \\
Mutation probability & 0.5 \\
Total bits in chromosome & 36 \\
\hline
\end{tabular}

Table 2. Parameter settings for the genetic algorithm.

The GA used here followed the generational model and had a population size of 11 (single strains) or 12 (consortia). Each solution was represented as a string of 9 values, encoding values for variables of environmental conditions. In this way, each solution encoded for a specific set of environmental conditions selected in the experiment (Table 3).

\begin{tabular}{lc}
\hline \multicolumn{2}{l}{ INITIAL RANGES OF VARIABLES } \\
\hline $\mathbf{p H}$ & $6.8-8.0$ every 0.1 unit \\
$\mathrm{NH}_{4} \mathrm{Cl}$ & $0.125-0.375(\mathrm{~g} / \mathrm{L})$ every $0.02 \mathrm{~g}$ \\
$\mathrm{NaH}_{2} \mathrm{PO}_{4}$ & $0.3-0.9(\mathrm{~g} / \mathrm{L})$ every $0.1 \mathrm{~g}$ \\
$\mathrm{NaHCO}_{3}$ & $1.25-3.75(\mathrm{~g} / \mathrm{L})$ every $0.2 \mathrm{~g}$ \\
$\mathrm{KCl}$ & $0.05-0.015(\mathrm{~g} / \mathrm{L})$ every $0.05 \mathrm{~g}$ \\
Acetate & $1-10 \mathrm{mM}$ every $1 \mathrm{mM}$ \\
Perchlorate & $60-400$ every $10 \mathrm{ppm}$ \\
Trace minerals & $0-10(\mathrm{ml} / \mathrm{L})$ every $1 \mathrm{ml} / \mathrm{L}$ \\
Vitamins & $0-10(\mathrm{ml} / \mathrm{L})$ every $1 \mathrm{ml} / \mathrm{L}$ \\
\hline
\end{tabular}

Table 3. Ranges of environmental conditions used for the optimization with the GA.

The initial population was generated at random. Fitness values were linearly rescaled, with $\mu^{\prime}=\mu$ and $f_{\max ^{\prime}}=0$. Roulette Wheel selection was used and no elitism was applied. Single crossover was performed on each pair of selected individuals with probability of 0.5 per bit. Over the course of eleven generations of optimization using a GA, a statistically significant 78.9-fold increase in average perchlorate degradation rate by Dechloromonas spp. KJ and Dechloromonas Miss R was observed, when optimization of consortia (P16 and Cw3) resulted in 109 and 143-fold increase in average perchlorate degradation rate (Kucharzyk et al., 2011) (Fig.3). The data obtained in this part of GA optimization provided a composition of an optimal medium for maintaining mixed cultures in further analysis and entailed the use of the GA to artificially construct a consortium from 10 isolates such that the consortium is optimized for the reduction of perchlorate (in progress).

In the next experiment, the GA used followed the generational model and has a population size of 10. A higher population size would most likely increase the efficiency of the optimization; however, we consider 12 experiments in fourfold the maximum number that is logistically feasible. Each solution was represented as a string of 10 bits, encoding the presence or absence of the corresponding microorganism. In this way, each solution was encoded for a specific microbial consortium. The initial population was generated at random. Fitness values were linearly rescaled with $\mu^{\prime}=\mu$ and $f_{\text {max }}=2 \mu$ (where $\mu$ and $\mu^{\prime}$ are the 
average fitness of the parent population before and after rescaling, respectively, and $f_{\max }{ }^{\prime}$ is the maximum fitness of the parent population after rescaling). If this yields negative values, the fitnesses is rescaled so that $\mu^{\prime}=\mu$ and $f_{\text {min }}=0$ (where $f_{\text {min }}$ is the minimum fitness of the parent population after rescaling). Roulette wheel selection is used, and elitism is applied. Single crossover is performed on each pair of selected individuals with a probability of 0.90 . Mutation is performed by flipping bit values with a probability of 0.01 per bit (Goldberg, 1989). To evaluate the fitness (perchlorate reduction rate/extent) of each individual in a generation, a method for assaying perchlorate concentrations using a fluorescent dye (Kucharzyk et al., 2010) is used.
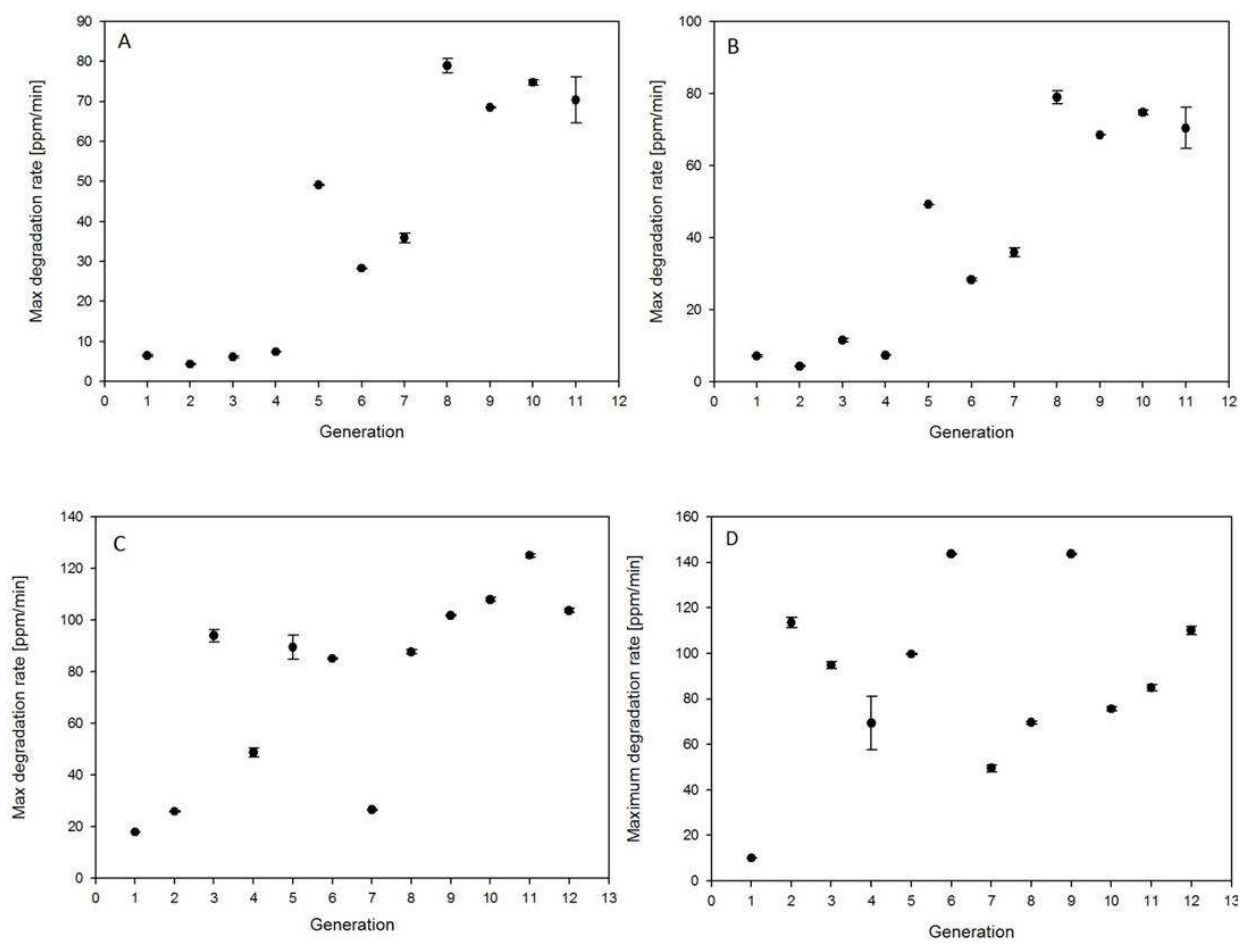

Fig. 3. Average degradation rates values of (A) Dechlorosoma sp. KJ, (B) Dechloromonas Miss R, (C) Cw3 consortium, (D) Pl6 consortium.

We expect that the analysis of the various fitness levels associated with particular strain combination show that the effect of single strains on the dynamics of mixed cultures will depend on what other strains the organism was combined with. The same strain can have positive, neutral or negative effect on between-generation variability.Similarly to results in several of Vandecasteele (2004) experiments, we expect the GA to be able to optimize efficient mixed microbial cultures in each of the experimental scenarios.

As Vandecasteele et al (2004) proposed, we believe that an ecological mechanism can be proposed to explain formation of highly effective microbial community. It appears as if early on in the optimization, the GA quickly eliminates certain strains from consortia. These could be strains that have a dominating overall negative influence on the productivity of the 
consortia. On the other hand, some strains quickly seemed to be positively selected. These could be strains that have a high biomass production and an overall positive influence on the consortia they are a member of. We also propose that the algorithm is seeking out clusters of highly productive organisms i.e. building blocks (Holland (1975) that function well together and is then recombining these clusters into larger scale consortia. Such groups of organisms could have a high biomass production because they have a positive influence on each other's growth or because they target different ranges of nutrient sources within the growth medium.

\subsubsection{Advantages and limitations of GA application}

The use of stochastic search procedures based on genetic algorithms (GAs) in the experimental optimization of media formulation has been lately applied in an efficacious manner compared to other methods, like statistical design of experiments (Park et al., 1998). The success of this approach is specially associated with the recent advances in the application of miniaturisation and parallelization techniques to bioreactors allowing the implementation of a large number of simple batch experiments which can be carried out simultaneously (Zafar et al., 2010). The careful manipulation of environmental conditions can result in precise shifts in the make-up of a microbial ecosystem, which can in turn translate to desirable changes in overall functionality. The successful execution of the manipulation of microbial systems in either of these two manners will often be a challenging experimental task (Vandecasteele, 2006). While statistical methods give better interpretation of an optimized response in term of variance, GA gives better point of prediction. GA is capable of exploring large variable spaces with the additional advantage of an evolutionary adaptation through selection, information exchange (crossing over), and mutation. The strategy of "survival of the fittest" is applied according to the optimization objectives (Zafar et al., 2010). GA has been successfully utilized for kinetic parameters estimation in biotechnological processes (Park et al., 1997; Sa'iz et al., 2003) such as alcoholic fermentation.

In the field of bioinformatics there have been a number of reports showing the capability of GA to effect data reduction in order to improve the performance of predictive models. For example, for classification problems using gene expression data (Li et al., 2001; Ooi \& Tan, 2003), improved classification accuracy was obtained following GA variable reduction. In a similar study, Chuzhanova et al. (1998) used GA with the Gamma (near-neighbour) test for feature selection of genetic sequence data, which again leads to improved classification results. GA optimization has also been applied to other bioinformatics-related problems such as sequence alignment (Notredame et al., 1998) and phylogenetic tree construction (Lewis, 1998). However, in work related to evolutionary algorithm optimization of laboratory processes, we observe that most research into noisy fitness functions make use of oversampling to improve the precision of the fitness estimate (Meekof \& Soule, 2010). This noise is inherent in both the sensors and in the variability of the processes themselves, particularly in applications to biological processes. GAs cannot effectively solve problems in which the only fitness measure is a single right/wrong measure (like decision problems), as there is no way to converge on the solution. In these cases, a random search may find a solution as quickly as a GA. However, if the situation allows the success/failure trial to be repeated giving (possibly) different results, then the ratio of successes to failures provides a suitable fitness measure. 


\subsection{Perchlorate phytoremediation}

\subsubsection{Background and theory}

Phytoremediation describes various in situ mechanisms by which vegetation is used to treat hazardous wastes. It is a demonstrated low-cost technology that has effectively treated a wide range of contaminants, involving perchlorate. The U.S. phytoremediation market now comprises $\$ 100-150$ million per year, or $0.5 \%$ of the total remediation market (Glass, 1999). In comparison, bioremediation comprises about $2 \%$ of the total remediation market (PilonSmiths, 2005). Commercial phytoremediation involves about $80 \%$ organic and $20 \%$ inorganic pollutants. The U.S. phytoremediation market has grown two to threefold in the past 5 years, from \$30-49 million in 1999 (Glass, 1999). The fact that phytoremediation is usually carried out in situ contributes to its cost-effectiveness and may reduce exposure of the polluted substrate to humans, wildlife, and the environment. Phytoremediation became popular among the general public as a "green clean" alternative (Pilon-Smiths, 2005).

\begin{tabular}{lll}
\hline $\begin{array}{c}\text { Phytoremediation } \\
\text { techniques }\end{array}$ & \multicolumn{1}{c}{ Mechanism } & \multicolumn{1}{c}{ Media } \\
\hline Rhizodegradation & Contaminant uptake by plant roots & $\begin{array}{l}\text { Surface water and } \\
\text { water pumped } \\
\text { through roots }\end{array}$ \\
\hline Phytotransformation & $\begin{array}{l}\text { Uptake and degradation of } \\
\text { contaminants }\end{array}$ & $\begin{array}{l}\text { Surface and } \\
\text { groundwater }\end{array}$ \\
\hline $\begin{array}{l}\text { Plant-assisted } \\
\text { bioremediation } \\
\text { (microbial) }\end{array}$ & $\begin{array}{l}\text { Degradation of contaminants in the } \\
\text { rhizosphere using microbial enzymes }\end{array}$ & $\begin{array}{l}\text { Groundwater, water } \\
\text { within the rhizosphere } \\
\text { and soil }\end{array}$ \\
\hline Phytoextraction & $\begin{array}{l}\text { Direct uptake of the contaminant by } \\
\text { the plant tissue with the removal from } \\
\text { the plant }\end{array}$ & $\begin{array}{l}\text { Soil } \\
\text { Phytostabilization }\end{array}$ \\
$\begin{array}{l}\text { Uptake of contaminants by the } \\
\text { rhizosphere and movement of the } \\
\text { contaminant to the aboveground parts } \\
\text { of the plant }\end{array}$ & $\begin{array}{l}\text { Groundwater, soil, } \\
\text { mining tailings }\end{array}$ \\
\hline Phytovolatilization & $\begin{array}{l}\text { Uptake and transpiration of } \\
\text { contaminants, primarily organic } \\
\text { compounds, by plants }\end{array}$ & Soil, groundwater \\
\hline Removal of aerial & $\begin{array}{l}\text { Uptake of various volatile organics by } \\
\text { leaves }\end{array}$ & Air \\
\hline
\end{tabular}

Table 4. Mechanisms for the removal of toxic contaminants from the environment and the techniques used in phytoremediation (Adapted from Singh et al., 2002).

Phytoremediation is a technique that takes advantage of plants' natural abilities to take up, accumulate and/or degrade constituents of their soil and water environment. It contains a variety of remediation techniques (Table 4) that include many treatment strategies.

Some forms of phytoremediation result in the destruction of the contaminant while others in the uptake of the contaminant into the plant roots, stems, and /or leaves (Van Nevel et al., 2007) (Fig.4). 


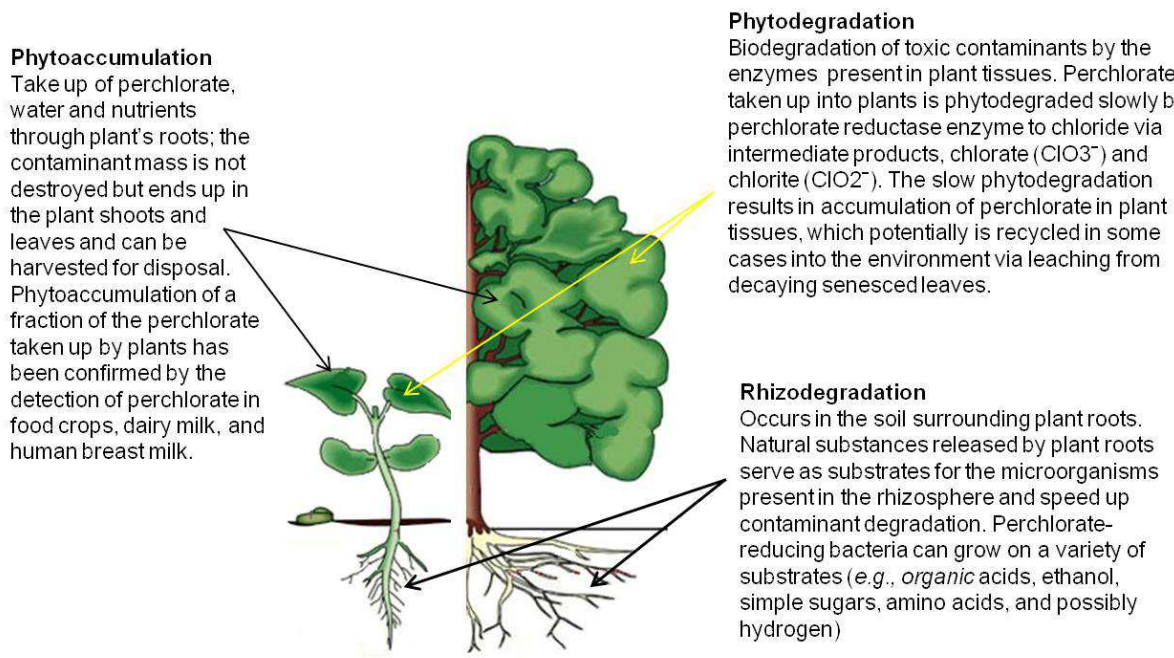

Fig. 4. Predominant processes occurring during perchlorate phytoremediation. Uptake and phytoaccumulation may pose risk to the environment because the slow phytodegradation result in accumulation of a fraction of the extracted perchlorate, primarily in the leaf tissue.

Phytoremediation avoids the need for soil excavation and transport, is relatively cheap, and causes less disruption to ecosystems than physical, chemical, or microbial remediation (Arthur et al., 2005). Plants can also stabilize contaminated soil and provide conditions favorable for microbial colonization of the rhizosphere for symbiotic degradation and detoxification of pollutants (Cherian \& Oliveira, 2005).

However, using plants for environmental clean-up often takes longer than other remediation techniques and is most suited to sites where contaminants are present at shallow levels within the reach of plant roots (Doty, 2008). The ability of certain plants to tolerate, detoxify, and store high concentrations of heavy metals in their tissues is of great importance for the development of phytoremediation and phytomining applications (Doran, 2009). However, the metal accumulating species are generally too small and slow-growing for direct practical use. Any attempt to genetically modify high-biomass plants such as tobacco to equip them with metal accumulator traits depends on our understanding of the key biochemical and physiological mechanisms involved. At the present time, although substantial progress has been made in these areas in recent years, much further work is required to elucidate the interactions between plant cells and toxic chemicals in the environment (Doran, 2009).

\subsubsection{Perchlorate phytoremediation status}

Nowadays, several plant-based experimental systems are available and these include cell extracts, dedifferentiated plant cell cultures such as callus and cell suspensions, differentiated organ cultures such as roots and shoots, explants such as leaf disks and excised roots, whole plants in hydroponic culture, whole plants in potted soil under 
greenhouse cultivation, and whole plants in the field (Chaudhry et al., 2005). Terrestrial plants that are able to remove perchlorate from groundwater and soil include species such as black willows (Salix nigra, Salix caroliniana), eucalyptus (Eucalyptus), and loblolly pine (Pinus taeda). Aquatic plants that have been successfully tested for perchlorate removal were water weed (Elodea cadadensis), parrot-feather (Myriophyllum aquaticum), duckweed (Spirodela polyrhiza) and cattails (Typha spp) (Nzegung \& McCutcheon, 2003). Perchlorate has also been detected in tobacco (Nicotiana tabacum L.) (Ellington et al., 2001), food crops such as cucumber (Cucumis sativus) and soybean (Glycine max) (Yu et al., 2004). Up to $300 \mathrm{mg} \mathrm{kg} / \mathrm{L}$ fresh water (on the basis of fresh wet weight) perchlorate uptake was found in salt cedar (Tamarix ramosissima) in Las Vegas Wash (Urbansky et al., 2000). Research up to date demonstrates that perchlorate is mainly accumulated in leaves rather than in roots. Laboratory studies also imply that phytodegradation in plant tissues occurs fairly slow (Nzegung \& McCutcheon, 2003).

Two major mechanisms for the phytodegradation of perchlorate have been identified: the uptake and phytodegradation, and rhizodegradation (Nzegung et al., 2004) (Fig.4). The mechanisms of perchlorate transport in plants are not fully understood. Perchlorate is a nonvolatile and highly mobile anion, which is not readily adsorbed by the negatively charged surface of most soils. Perchlorate transport in plants might be linked with passive transport of water across the plasma membranes of root cells (i.e., simple diffusion or facilitated diffusion) (Tan et al., 2004). Perchlorate uptake may be also dependent on water mass flow or transportation. As long as it is not leached or precipitated as a salt, perchlorate in the rhizosphere has two main fates: it is either taken up by a plant or degraded in the rhizosphere. Under anaerobic condition, rhizodegradation dominates and is facilitated by low availability of electron donors (Nzengugn \& McCutcheon, 2003) and high availability of electron donors. Certain anaerobic bacteria (perchlorate reducers) are necessary for this process, and they are capable of reducing perchlorate to chloride via chlorate and chlorite intermediates through a stepwise reaction (Urbansky, 2000):

$$
\mathrm{ClO}_{4}^{-} \rightarrow \mathrm{ClO}_{3}^{-} \rightarrow \mathrm{ClO}_{2}^{-} \rightarrow \mathrm{Cl}
$$

In anaerobic microcosms, direct evidence for this stepwise reduction has been demonstrated by the appearance of chlorate and chloride and disappearance of perchlorate in the rhizosphere; chlorite was nor detected and is believed to be a short-lived intermediate (Nzengung et al., 2004). Plant uptake of perchlorate dominates under the aerobic conditions and the compound is taken up by roots and stored in tissues where it may be phytodegraded (Nzengung et al., 2004). Phytodegradation appears to be an enzymatically driven process that takes place on the order of hours, whereas rhizodegradation takes place on the order of days. There are very limited data on the presence of chlorate and chlorite intermediates within plant tissues after perchlorate uptake. To date Aken and Schnoor (2002) have provided the most unequivocal evidence for perchlorate phytodegradation by using radiolabeled perchlorate $\left({ }^{36} \mathrm{ClO}_{4}^{-}\right)$in a 4-week uptake experiment using hybrid poplar trees (Pinus deltoids $x$ nigra). Radioactive chlorate, chlorite and chloride were detected in the solution after 30 days. These data provide evidence that perchlorate is metabolized within poplar plant tissues through chlorate and chlorite intermediates to chloride, which is then exuded from the plant roots to the surrounding soil. It remains unknown whether other plant species are capable of perchlorate phytodegradation or if phytodegradation differs in plant organs or as a function of tissue age (Aken \& Schnoor, 2002). 


\subsubsection{Advantages and limitations}

Phytoremediation is recognized as a fast-growing and cost-effective technology to remediate hazardous toxic metals from contaminated sites. However, delivering a remediation system that is applicable to specific contaminated soils is a relatively recent focus. It has the advantages of low cost, high public acceptance and low amounts of secondary waste products (Singh et al., 2003). Phytoremediation can treat other co-contaminants such as chlorinated solvents and explosives including (N-nitrosodimethylamine) (Yifru \& Nzegung, 2006). Table 5, summarizes the advantages and limitations and reveals that many of them are a direct result of the biological aspect of this type of treatment system.

\begin{tabular}{ll}
\hline Advantages & Limitations \\
\hline Cost effective & Depth of soil and climate restrictions \\
Remediation of large areas of soil & Slower than conventional methods \\
Environmentally friendly & Seasonally effective \\
Phytoremediation sites are low & $\begin{array}{l}\text { Effective only for moderate hydrophobic } \\
\text { contaminants }\end{array}$ \\
Involvenance & No direct regulations are known yet \\
In situ & Contaminants may enter food chain by \\
Soils remain in place, are usable & animal consumption \\
following treatment & Accumulation of toxic contaminants may be \\
Transfer is more rapid than natural & toxic to plants \\
attenuation & Limited mass transfer associated with \\
Fewer secondary wastes & biotreatments \\
& Climatic changes may diversify the \\
Fewer air and water emissions & phytodegradation \\
\hline
\end{tabular}

Table 5. Advantages and limitations of phytoremediation of perchlorate and its cocontaminants.

The limitations of perchlorate phytoremediation include depth and climate restrictions as well as the potential for transfer for contaminants from soil and groundwater into the food chain (Nzgengung et al., 2009). Phytoremediation of perchlorate is also relatively slow comparing to its microbial reduction and it is subject to the seasonal climate variations. Perchlorate also may have a toxic effect on certain plant species and hyperaccumulating in the tissues could be toxic to the plant biodegrading it itself. Basic research is still needed by plant biologists for a deeper understanding of plant decontamination processes. The concept of genetically modified transgenic plants and their innovative genes that regulate toxic metal uptake is today's cutting-edge research (Rajagopalan et al., 2006).

\section{Microbial $\mathrm{ClO}_{4}{ }^{-}$reduction with $\mathrm{Fe}(0)$ and inorganic electron donors}

\subsection{Background and theory}

Inorganic electron donors can overcome the disadvantages of organic substrates such as acetate or lactate, and thus are currently the focus of the study for biological reduction of perchlorate. Batch and continuous flow bioreactors have been evaluated utilizing $\mathrm{H}_{2}$ to support autotrophic perchlorate reduction (Nerenberg \& Ritmann, 2004). Hydrogen gas $(5 \%)$, along with carbon dioxide, was provided to achieve $30-39 \%$ perchlorate reduction in 
an autotrophic bioreactor. Although $\mathrm{H}_{2}$ is a good energy substrate, its handling and storage may be a safety issue. $\mathrm{Fe}(0)$ is a strong reducing agent $\left(\mathrm{E}^{0}=-0.44 \mathrm{~V}\right)$, and has been used in recent years to treat oxidized pollutants such as nitroaromatics, nitramines, and azo dyes through reductive transformation (Perey et al., 2002). It is also successfully applied in permeable reactive barriers for the remediation of chlorinated volatile organic compounds (Lai et al., 2006). Thermodynamically, perchlorate is readily reducible by $\mathrm{Fe}(0)\left(\Delta \mathrm{G}^{0^{\prime}}\right)-596.27$ $\mathrm{kcal} \mathrm{mol}^{-1}$ ), however the energy barrier to the reduction is large (Moore et al., 2003) and the chemical reduction is too slow for the zero-valent iron to be used in situ for remediation. Under anaerobic conditions, iron corrosion produces hydrogen gas through the reduction of protons (Eq. 2) and in the presence of hydrogenotrophic organisms the cathodic hydrogen may be utilized to degrade perchlorate (Son et al., 2006), nitrate, chlorinated solvents and sulfate (Weathers et al., 1997).

$$
\mathrm{Fe}^{0}+2 \mathrm{H}_{2} \mathrm{O} \rightarrow \mathrm{Fe}_{2}{ }^{+}+2 \mathrm{OH}^{-}+\mathrm{H}_{2} \text { (gas) }
$$

$\mathrm{Fe}_{2}{ }^{+}$and $\mathrm{S}_{2}-$ are examples of other inorganic electron donors used by $\mathrm{ClO}_{4}^{-}$-reducing bacteria (Achenbach et al., 2006). Granular $\mathrm{S}_{0}$ in packed bed bioreactors has been used successfully as electron-donating substrate in autotrophic denitrification processes for drinking water (Koeing \& Liu, 2001; $\mathrm{Xu}$ et al., 2003). Granular $\mathrm{S}_{0}$ is insoluble and thus provides a slow release supply of electrons on demand, offering advantages of low maintenance and low cost. Therefore it's potential as an electron-substrate for $\mathrm{ClO}_{4}^{-}$reduction is being explored. The expected stoichiometry of the reaction is as follows:

$$
3 \mathrm{ClO}_{4}^{-}+4 \mathrm{~S}_{0}+4 \mathrm{H}_{2} \mathrm{O} \rightarrow 4 \mathrm{SO}_{4}^{2-}+8 \mathrm{H}^{+}+3 \mathrm{Cl}^{-}
$$

For the first time Ju et al. (2008) evaluated various inocula sources for their ability to utilize inorganic compounds such as $\mathrm{H}_{2}, \mathrm{Fe}^{0}$ and reduced sulfur compounds (i.e., $\mathrm{S}^{0}, \mathrm{~S}_{2}^{-}$and $\mathrm{S}_{2} \mathrm{O}_{2}{ }^{3-}$ ) as electron-donating substrates for the chemolithotrophic reduction of perchlorate. The coupling of perchlorate reduction to chloride with elemental sulfur oxidation to sulfate is an exergonic reaction with standard Gibb's free energy $\left(\Delta \mathrm{G}^{0^{\prime}}\right)$ of $-1146.9 \mathrm{~kJ} \mathrm{~mol}^{-1} \mathrm{ClO}_{4^{-}}(37.6$ mol ATP mol ${ }^{-1} \mathrm{ClO}_{4}^{-}$). This chemolithotrophic reaction is bioenergetically comparable to chemoorganotrophic perchlorate reduction, for example the $\left(\Delta \mathrm{G}^{\prime}\right)$ of perchlorate reduction

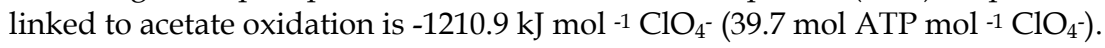

\subsection{Technology development status}

The most recent studies on microbial perchlorate reduction were conducted by Shrout et al. (2005). They ran the experiments in the presence of zero-valent iron using a mixed culture obtained from an anaerobic digester, however, they reported that the addition of Fe (0) to the anaerobic culture resulted in slower rate of perchlorate reduction. The inhibitory effect of zero-valent iron on perchlorate was attributed to the increase in $\mathrm{pH}$ and encapsulation of bacteria by iron precipitates. High concentrations of bicarbonate $(1260 \mathrm{mg} / \mathrm{L})$ and phosphate $(430 \mathrm{mg} / \mathrm{L})$ in the culture media resulted in the formation of vivianite, $\mathrm{Fe}_{3}\left(\mathrm{PO}_{4}\right)_{2}$, and siderite, $\mathrm{FeCO}_{3}$, the major iron precipitates identified on Shrout et al. (2005) research, but $\mathrm{Yu}$ et al. (2006) claim they are not likely to occur in typical groundwater conditions. In contrast, $\mathrm{Yu}$ et al. (2006) showed that zero-valent iron was capable of serving as electron donor for perchlorate reduction by providing hydrogen to a hydrogen utilizing autotroph (Dechloromonas sp. HZ). Initially, the activity of Dechloromonas sp. HZ pure culture was 
strongly dependent on solution $\mathrm{pH}$; however, once perchlorate reduction was established, the microbial reduction process was sustained even at pH 9 (Son et al., 2006). While Yu et al. demonstrated the feasibility of microbial perchlorate reduction supported by zero-valent iron, their experimental conditions were not typical of environment conditions commonly found in natural and engineered systems. As the logical extension to the proof-of-concept studies employing batch pure cultures studies, flow-through column studies with environmentally relevant mixed cultures were needed to further promote and enhance the potential of the integrated $\mathrm{Fe}(0)$-cell system for perchlorate remediation.

The study of Son et al. (2006) investigated the feasibility of integrated iron-biological perchlorate reduction through both batch and column reactor experiments. The study proved the complete disappearance of perchlorate only in the presence of $\mathrm{Fe}(0)$ (Fig.5A), $\mathrm{H}_{2}$ and acetate. Perchlorate $(65 \mathrm{mg} / \mathrm{L})$ in the reactors containing both $\mathrm{Fe}(0)$ and cells was completely removed to below the detection limit of $0.02 \mathrm{mg} / \mathrm{L}$ in 8 days. In contrast, only $15 \%$ of the initial perchlorate was removed in the $\mathrm{Fe}(0)$ - only reactors (no cells) over 10 days, indicating iron alone was not effective in removing perchlorate. A chloride balance performed in the batch experiments using high-purity iron (Alfa Aesar, Ward Hill, MA) indicated that perchlorate was reductively transformed to chloride $\left(\mathrm{Cl}^{-}\right)$(Fig5B). In this integrated iron-biological system, iron could serve as a precursor of hydrogen gas, which could be used as electron donor for mixed cultures to reduce perchlorate.
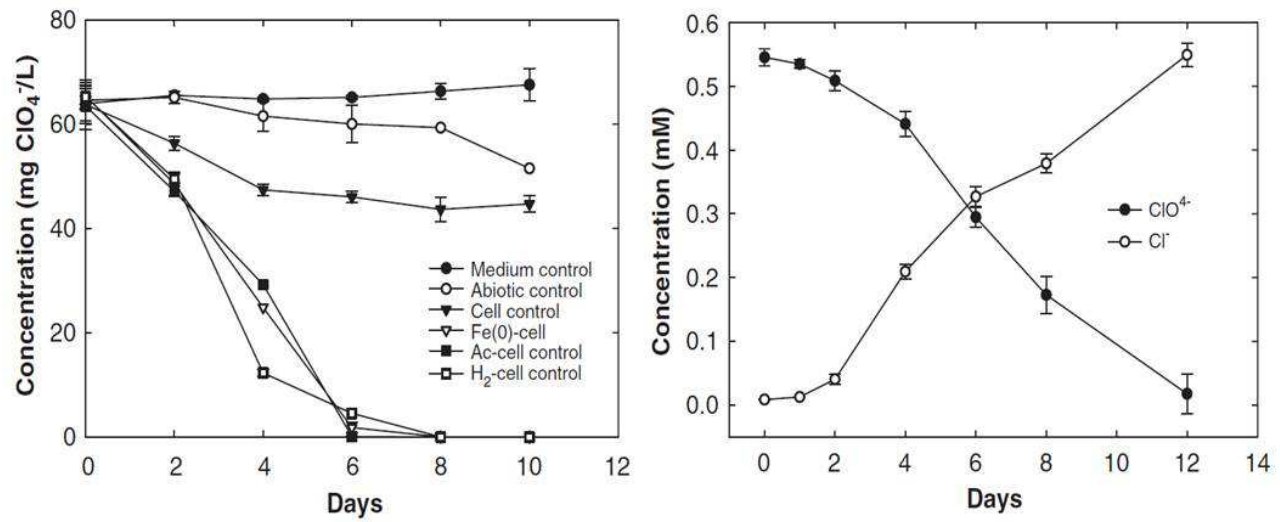

Fig. 5. A. Perchlorate removals in the iron-mediated microbial culture. Fe(0)-cell batch reactor contained $2 \mathrm{~g}$ of Master Builder's cast iron. B. Chloride balance in microbial perchlorate reduction by pure iron granules. Initial concentration of perchlorate was $55 \mathrm{mg} / \mathrm{L}$. Batch reactor contained $2 \mathrm{~g}$ of Alfa Aesar high purity iron granules. (Adopted from Son et al., 2006).

Bardiya and Bae (2005) studied $\mathrm{ClO}_{4}$ - reduction with $\mathrm{S}^{0}$ and $\mathrm{S}_{2} \mathrm{O}_{2}{ }^{3-}$ as electron donors with various inocula sources such as digester sludge and primary settled sludge, but their results showed no perchlorate removal after 25-d incubation. Ju et al. (2008) experimental data showed that these inocula sources could utilize the reduced sulfur compounds to support $\mathrm{ClO}_{4}^{-}$reduction, albeit at lower rates compared with $\mathrm{H}_{2}$. However, when the $\mathrm{S}^{0}$-oxidizing enrichment culture was used as the inoculum, the rates of $\mathrm{ClO}_{4}$-reduction were significantly 
improved (Ju et al., 2008). Testing the enrichment culture utilizing $S^{0}$ sulfur as an electron donor revealed that $\mathrm{S}^{0}$ was the best electron donor with more than $95 \% \mathrm{ClO}_{4}$ - removed after seven days of incubation (Fig.6a) and $\mathrm{S}_{2} \mathrm{O}_{3}{ }^{2-}$ was the second best electron donor for perchlorate reduction. The patterns observed in perchlorate reduction were reflected in the $\mathrm{Cl}^{-}$and $\mathrm{SO}_{4}{ }^{2-}$ production.

$\mathrm{S}^{0}$ has been discovered as a novel electron donor for microbial perchlorate reduction. Because it is insoluble in water, $\mathrm{S}^{0}$ granules would be particularly suitable as a slow release electron donor for packed-bed bioreactors intended for perchlorate reduction. A comparable processes known as sulfur limestone autotrophic denitrification has been used for $\mathrm{NO}_{3}$ removal in wastewater and drinking water (Flere \& Zhang, 1999; Koeing \& Liu, 2001).
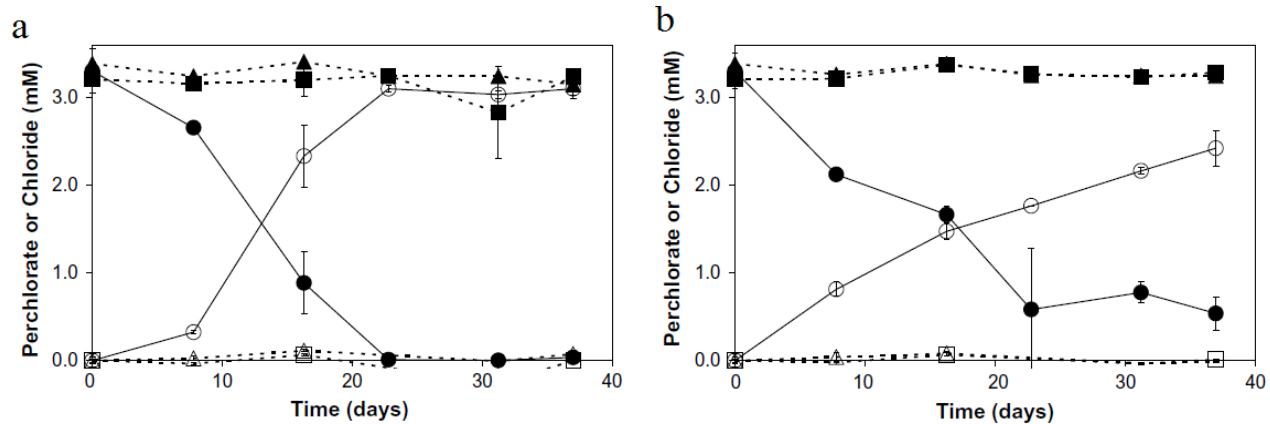

Fig. 6. Perchlorate reduction by various electron donors inoculated with activated sludge (5\% v/v). (a) $\mathrm{S}^{0}\left(0.64 \mathrm{~g} \mathrm{l}^{1}{ }^{1}\right)$ as electron donor. (b) $\mathrm{Fe}^{0}(3.4 \mathrm{~g} \mathrm{l-1})$ as electron donor. Legend: (filled circles) $\mathrm{ClO}_{4^{-}}$with live inoculum; (filled triangles) $\mathrm{ClO}_{4^{-}}$in heat-killed inoculum control; (filled squares) $\mathrm{ClO}_{4}^{-}$in medium only control; (empty circles) $\mathrm{Cl}^{-}$with live inoculum; (empty triangles) $\mathrm{Cl}^{-}$in heat-killed inoculum control; (empty squares) $\mathrm{Cl}^{-}$in medium only control. (Adapted from Ju et al., 2008).

\section{Conclusions}

A variety of perchlorate remediation technologies are currently commercially available. One of them - biological degradation involves perchlorate-reducing bacteria (PRBs), which are widespread in the environment. PRBs have the ability to grow in either the presence or absence of air, provided proper nutrients are available in the environment. Both in situ and ex situ biological treatment systems have already been applied at full scale to treat perchlorate.

Implementation of novel techniques such as optimization and creation of microbial consortia using a Genetic Algorithm have a great a chance to improve the existing technology. Here, genetic algorithms could become a tool in environmental microbiology for an efficient control of the functioning of natural and undefined microbial ecosystems. Phytoremediation, a fairly new technology, is anticipated to be most applicable to vadose zone source areas in soil, groundwater, or surface runoff. Field-scale application of phytoremediation would require adequate space to establish the plants, and they may need special handling afterwards, if rhizodegradation is not enhanced and perchlorate salts 
accumulate in the plant tissues. Complete removal of perchlorate by iron-supported anaerobic cultures could be achieved in bench-scale iron columns where zero-valent iron has a potential as a source of electrons in collaboration with biological perchlorate degradation. Use of zero-valent iron may eliminate the need to continually supply electron donors such as organic substrates or explosive hydrogen gas.

\section{References}

Achenbach, L.A., Bender, K.S., Sun,Y., \& Coates,J.D. (2006). The Biochemistry and Genetics of Microbial Perchlorate Reduction. In Perchlorate. Environmental Occurrance, Interactions and Treatment. Springer Science and Business Media, Inc., pp. 297-310

Aken, B. \& Schnoor, J.L. (2002). Evidence of perchlorate removal in plant tissues (Poplar trees) using radio-labeled $36 \mathrm{ClO}_{4}^{-}$. Env Sci and Technol, 36, 2783-2788.

Arthur, E.L., Rice, P.J., Anderson, T.A., Baladi, S.M., Henderson, K.L.D. \& Coats, J.R. (2005). Phytoremediation-An overview. Crit Rev Plant Sci, 24:109-122 Aziz, C. \& Hatzinger, P.B. (2009). Perchlorate sources, source identification and analytical methods, In Situ Bioremediation of Perchlorate in Groundwater. Stroo,H.F. and Ward, C.H. (eds). Springer Science and Business Medi

Aziz, C. \& Hatzinger, P.B. (2009). Perchlorate sources, source identification and analytical methods, In Situ Bioremediation of Perchlorate in Groundwater. Stroo,H.F. and Ward, C.H. (eds). Springer Science and Business Medi

Bapat, P. M. \& Wangikar, P. P. (2004). Optimization of rifamycin B fermentation in shake flasks via a machine-learning-based approach Biotechnol. Bioeng., 86, 201-208

Bardiya, N. \& Bae, J. (2005). Bioremediation potential of a perchlorate-enriched sewage 556 sludge consortium. Chemosphere. 58:83-90

Blount, B.C., Pirkle, J.L., Osterloh, J.D., Valentin-Blasini, L. \& Caldwell, K.L. (2006). Urinary perchlorate and thyroid hormone levels in adolescent and adult men and women living in the United States. Env Health Perspectives 114 : 1865-1871

Brenner, K., You, L. \& Arnold, F.H. (2008). Engineering microbial consortia: a new frontier in synthetic biology. Trends in Biotchnol, Vol. 26 No.9

Bryan, E. H. (1966). Application of the chlorate BOD procedure to routine measurement of wastewater strength. Journal of Water Pollution Control Federation 38:1350-1362.

Chaudhry, Q., Blom-Zandstra, M., Gupta, S. \& Joner, E.J. (2005). Utilising the synergy between plants and rhizosphere microorganisms to enhance breakdown of organic pollutants in the environment. Environ Sci Pollut Res, 12:34-48.

Cherian, S. \& Oliveira, M.M. (2005). Transgenic plants in phytoremediation:Recent advances and new possibilities. Environ Sci Technol, 39:9377-9390.

Chuzhanova, N.A., Jones, A.J. \&Margetts, S. (1998). Feature selection for genetic sequence classification. Bioinformatics, 14: 139-143.

Cunniff, S. (2006). Perchlorate: Challenges and lessons. In Perchlorate: Environmental occurrance, Interactions and treatment. Gu,B. and Coates,J.D. (eds). New York, NY: Springer Science and Business Media Inc., pp. 1-15. 
Coates, J.D., Michaelidou,U., O'Connor, S.M., Bruce, R.A. \& Achenbach, L.A. (2000). The diverse microbiology of (per)chlorate reduction., p. 257-270. In E.D. Urbansky (ed.), Perchlorate in the Environment. Kluwer Academic/Plenum, New York.

de Groot, G. N. \& Stouthamer, A.H. (1969). Regulation of reductase formation in Proteus mirabilis. I. Formation of reductases and enzymes of the formic hydrogenlyase complex in the wild type and in chlorate resistant mutants. Archives of Microbiology, 66:220-233.

Desai, K. M., Akolkar, S. K., Badhe, Y. P., Tambe, S. S. \& Lele, S. S. (2006). Optimization of fermentation media for exopolysaccharide production from Lactobacillus plantarum using artificial intelligence based techniques. Process Biochemistry, 41:1842-1848

Doty, S.L. (2008). Enhancing phytoremediation through the use of transgenics and endophytes. New Phytol, 179:318-333.

Doran, P.M. (2009). Application of Plant Tissue Cultures in Phytoremediation Research: Incentives and Limitations. Biotechnol and Bioengineering, 103

Ederer, M., Kucharzyk, K.K., Crawford, R.L. \& Hess, T.F. (2011). Microbial reduction of chlorate and perchlorate: phylogenetic analysis of the genes encoding the degradation pathways. Perchlorates Production, Uses and Health Effects. Nova Science Publishers, Inc (in print)

Ellington, J.J., Wolfe, N.L., Garrison, A.W., Evans, J.J \& Teng, Q. (2001). Determination of Perchlorate in Tobacco Plants and Tobacco Products; Environ. Sci. Technol, 35:31133218

Etschmann, M.M.W., Sell, D. \& Schrader, J. (2004). Medium optimization for the production of the aroma compound 2-phenylethanol using a genetic algorithm. J Mol Catal B Enzym 29:187-193

EWG (2007). Rocket fuel in Drinking water: perchlorate pollution spreading nationwide. Copyright 2007-2009, Environmental Working Group. All Rights Reserved. 2007

Fang, B. S., Chen, H.W., Xie, X.L., Wan, N. \& Hu, Z.D. (2003). Using genetic algorithms coupling neural networks in a study of xylitol production: medium optimization. Process Biochem, 38:979-985

Flere, J.M. \& Zhang, T.C. (1999). Nitrate removal with sulfur-limestone autotrophic denitrification processes. J. Environ. Eng.-ASCE 125, 721-729

Franco-Lara, E., Link, H. \& Weuster-Botz, D. (2006). Evaluation of artificial neural network for modeling and optimization of medium composition with a genetic algorithm. Process Biochemistry, 41: 2200-2206

Glass, D.J. (1999). U.S. and International Markets for phytoremediation, 1999-2000, Needham, MA: D, Glass Assoc.

Gullick, R.W., LeChevallier, M. \& Barhorst, T. (2001). Occurrence of perchlorate in drinking water sources. J Am Water Works Assoc, 93:66-77

Goldberg, D. E. (1989). Genetic algorithms in search, optimization \& machine learning. Reading, MA: Addison-Wesley 
Hecht, M.H., Kounaves, S.P., Quinn, R.C., West, S.J., Young, S.M. \& Ming, D.W.(2009) Detection of perchlorate and the soluble chemistry of martian soil at the Phoenix lander site. Science, 325: 64-67

Holland, J. H. (1975). Adaptation in natural and artificial systems: an introductory analysis with applications to biology control and artificial intelligence. Ann Arbor, MI: University of Michigan Press.

Jackson, P.E., Joseph, P., Patil, L., Tan, K., Smith, P.N., Yu, L., \& Anderson,T.A. (2005). Perchlorate accumulationin forage and edible vegetation. J of Ag Food Chemi, 53: 369-373

Jackson, W.A., Anderon, T., Harvey, G.J., Orris, G.J., Rajagopalan, S., \& Kang,N. (2006). Occurrence and formation of Non-Anthropogenic perchlorate. In Perchlorate: Environmental Occurrance, Interaction and Treatment. Gu,B. and Coates,J.D. (eds). pp. 49-69

Jarvis, R.M. \& Goodcare, R. (2005). Genetic algorithm optimization for pre-processing and variable selection of spectroscopic data. Bioinformatics, 21 (7): 860-868

Ju, X., Sierra-Alvarez, R., Field, J.A., Byrnes, D.J., Bentley, H. \& Bentley, R. (2008). Microbial perchlorate reduction with elemental sulphur and other inorganic electron donors. Chemosphere 71: 114-121

Kambam, P.K., Eriksen, D.T., Lajoie, J., Sayut,D.J. \& Sun, L.. (2008). Design and mathematical modeling of a synthetic symbiotic ecosystem. IET Syst. Biol, 2:33-38

Kegley, S.E., Hill, B.R., Orme, S. \& Choi,A.H. (2008). Sodium Chlorate - Identification, toxicity, use, water pollution potential, ecological toxicity and regulatory information. PAN pesticide Dababase, Pesticide Action Network, North America . San Francisco, CA.

Keller, L. \& Surette, M.G. (2006). Communication in bacteria: an ecological and evolutionary perspective. Nat. Rev.Microbiol, 4:249-258

Kirk, A.B., Martinelango, P.K., Tian,K., Aniruddha,D., Smith E.E. \& DasGupta,P.K. (2005). Perchlorate and iodide in dairy and breast milk. Env Sci and Technol 39: 2011-201

Koenig, A. \& Liu, L.H. (2001). Kinetic model of autotrophic denitrification in sulphur packed-bed reactors. Water Res. 35, 1969-1978

Kucharzyk, K.H., Crawford, R.L., Cosens, B. \& Hess, T.F. (2009). Development of drinking water standards for perchlorate in the United States. J Environ Manage, 91(2), 303 10.

Kucharzyk, K.H, R. L. Crawford, A.J. Paszczynski \& Hess, T.F. (2010). A Method for Assaying Perchlorate Concentration in Microbial Cultures Using the Fluorescent Dye Resazurin J. Microbiol. Methods, 81(1):26-32

Kucharzyk, K.H., Crawford, R.L., Paszczynski, A.J., Soule, T. \& Hess, T.F. (2011). Maximizing microbial perchlorate degradation using a genetic algorithm: media optimization. Appl Environ Microbiol, (in progress).

Lewis, P. (1998).Agenetic algorithm for maximum-likelihood phylogeny inference using nucleotide sequence data. Mol. Biol. Evol, 15:277-283.

Li, L.,Weinberg, C.R., Darden,T.A. \& Pederson,L.G. (2001). Gene selection for sample classification based on gene expression data: study of sensitivity to choice of parameters of the GA/KNN method. Bioinformatics, 17, 1131-1142 
Li, S. X, D. Xing, H. M. Qin, X. B. Yang, and S.C. Tan. (2004). Experimental study on genetic algorithms of medium optimization for oil-degradation. Chinese J. Analyt. Chem, 32:481-484.

Martin, A. \& Sivagurunathan, M. (2003). Optimization of the biodegradation of naphthalene by a microorganism isolated from petroleum contamination soil. Communication in Ag and Appl Biol Sci, v. 68 (2Pt A), 175-180.

Meekhof,T. \& Soule, T. (2010). Noise pressure: systematic overestimation of population fitness in genetic algorithms with noisy fitness functions. GECCO 2010: 833-834

Moore, A.M., De Leon, C.H. \& Young, M. (2003). Rate and extent of aqueous perchlorate removal by iron surfaces. Environ. Sci.Technol. 37, 3189-3198

Moreira, G. A., Michelouf, G. A., Beccaria, A. J. \& Goicoechea, H. C.(2007) Optimization of

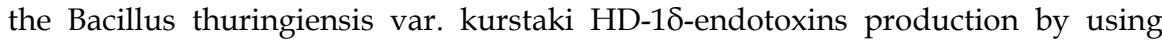
experimental mixture design and artificial neural networks. Biochem Engineering Journal, v. 35:48-55

Motzer, W. E. (2001). Perchlorate: problems, detection, and solutions. Environmental Forensics, 2 (4):301-311.

Muffler, K., Retzlaff, M., van Pee, K-H. \& Ulber, R. (2004). Optimization of halogenase enzyme activity by application of a genetic algorithm. J Biotechnol 127: 425-433

Muffler, K.,Retzlaff, M., P'ee, K-H., Ulber, R. (2007). Optimisation of halogenase enzyme activity by application of a genetic algorithm. J Biotechnol, 127:425-433

Nagata, Y. \& Chu, H. (2003). Optimization of a fermentation medium using neural networks and genetic algorithms. Biotechnol Letters 25: 1837-1842

National Research Council (2005). Health Implications of Perchlorate Ingestion Committee to Assess the Health Implications of Perchlorate Ingestion. National Academy of Sciences, p. 9.

Nerenberg, R., Rittmann, B.E. \& Najm, I. (2002). Perchlorate reduction in a hydrogen-based membrane-biofilm reactor. J. Am. Water Works Assoc. 94, 103-114

Notredame,C., Holm,L. and Higgins,D. (1998). Coffee: an objective function for multiple sequence alignments. Bioinformatics, 14, 407-422.

Nzengung,V.A. \& McCutcheon,S.C. (2003). Phytoremediation of perchlorate. In McCutcheon, S.C. \& Schnoor, J.L., eds Phytoremediation: transformation and control of contaminants. Wiley-Interscience Publichers, Hoboken, NJ, USA, pp 863885

Nzegung, V.A, Penning, H. \& O’Niell, W. (2004). Mechanistic changes during phytoremediation of perchlorate under different root zone conditions. Int J Phytoremediation, 6:63-83

Nzengung, V.A., Lieberman, M.T., Stroo, H.F. \& Evans, P.J. (2009) Emerging technologies for perchlorate remediation. In Ward, C.H \& Stroo, H.F. eds In situ bioremediation of perchlorate in groundwater. Springer Science Business Media, LLC, New York, NY, USA

Orris, G.J., Harvey, G.J., Tsui, D.T., \& Eldrige,J.E. (2003). Preliminary analyses for perchlorate in selected ntural materials and their derivative products. US Geological Survey, Open field Report 03-314. 
Ooi, C.H. \& Tan, P. (2003). Genetic algorithms applied to multi-class prediction for the analysis of gene expression data. Bioinformatics, 19:37-44.

Park, T.Y. \& Fromet, G.F. (1998). A hybrid genetic algorithm for the estimation of parameters in detailed kinetic models. Comp Chem Eng, 22:103-10.

Patil, S. V., Jayaraman, V.K. \& Kulkarni, B.D. (2002). Optimization of media by evolutionary algorithms for production of polyols. Appl. Biochem. Biotechnol, 102-103:119-128.

Perey, J.R., Chiu, P.C., Huang, C.P. \& Cha, D.K. (2002). Zero-valent iron pretreatment for enhancing the biodegradability of azo dyes. Water Environ. Res. 74, 221-225

Pilon-Smiths, E. (2005). Phytoremediation. Annu Rev Plant Biol, 56: 15-39

Rao, S.C., Sathish, T., Mahalaxmi, M., Laxmi, G.S., Rao, S.R. \& Prakasham, R.S. (2007). Modelling and Optimization of fermentation factors for enhancement of alkaline protease production by isolated Bacillus circulans using feed-forward neural network and genetic algorithm. J Appl Microbiol, 104 : 889-898

Rajagopalan, S., Anderson,T.A., Fahlquist,L., Rainwater,K.A., Ridley,M., and Jackson,W.A. (2006). Widespread Presence of Naturally Occurring Perchlorate in High Plains of Texas and New Mexico. Environmental Science \& Technology, 40: 3156-3162

Reeves, C. R. (1993).Using genetic algorithms with small populations. In Proceeding of the Fifth International Conference on Genetic Algorihms, pp. 92-99. Edited by S. Forrest. San Mateo, CA.

Roldan, M. D., F. Reyes, C. Moreno-Vivian, and F. Castillo. (1994). Chlorate and nitrate reduction in phototrophic bacteria Rhodobacter capsulatus and Rhodobacter sphaeroides. Curr. Microbiol, 29:241-245.

Stewart, V. (1988). Nitrate respiration in relation to facultative metabolism in enterobacteria. Microbiol. Rev, 52:190-232.

Sa'iz, J.M.G., Pizarro, C., Vidal, D.G. (2003). Evaluation of kinetic models for industrial acetic fermentation: proposal of a new model optimized by genetic algorithm. Biotechnol Prog, 19:599-611.

Schugerl, K. (2001) (2001). Progress in monitoring, modeling and control of bioprocess during the last 20 years. J Biotechnol, 85:149-73.

Sellers,K., Alsop,W., Clough,S., Hoyt,M., Pugh,B., Robb,J. \& Weeks,K. (2007) Perchlorate. Environmental Problems and Solutions. New York, NY: CRC Taylor and Francis Group.

Shrout, J.D., Williams, A.G.B., Scherer, M.M. \& Parkin, G.F., (2005). Inhibition of bacterial perchlorate reduction by zero-valent iron. Biodegrad 16, 23-32

Singh,O.V., Labana,S., Pandey,G., Budhiraja,R. \& Jain, R.K. (2003). Phytoremediation: an overview of metallic ion decontamination from soil. Appl Microbiol Biotechnol, 61:405-412

Son, A., Lee, J., Chiu, P.C., Kim, B.J., Cha, D.K. (2006). Microbial reduction of perchlorate with zero-valent iron. Water Research 40: 2027-2032

Stroo, H.F., Loehr, R.C. \& Ward, H. (2009). In situ bioremediation of perchlorate in groundwater: an overview. In: In situ bioremediation of perchlorate in groundwater. Ward, C.H., 1-13, Springer Science+Business Media, LCC, New York, USA 
Tan,K., Anderson,T.A., Jones,M.W., Smith, P.N. \& Jackson, J.A.W.(2004). Accumulation of Perchlorate in Aquatic and Terrestrial Plants at a Field Scale. Environ.Qual, 33:1638 1646

Urbansky,E.T. (2000) Quantitation of perchlorate ion: practices and advances applied to the analysis of common matrices. Critical Review of Analytical Chemistry.

Urbansky, E.T. (2002). Perchlorate environmental contamination: Toxicological review and risk characterization. Perchlorate in the Environment. Kluwer Academic/ Plenum, New York USEPA. NCEA-1-0503, External Review Draft. National Center for Environmental Assessment, Office of Research Development, USEPA, Washington, DC, USA.

USEPA (2002). Report on the Peer Review of the U.S. Environmental Protection Agency's Draft External Review Document "Perchlorate Environmental Contamination: Toxicological Review and Risk Characterization".

Vandecasteele, F.P.J., T.F. Hess \& Crawford, R.L. (2004). Constructing microbial consortia with minimal growth using a genetic algorithm, pp. 123-129. In G. R. Raidl, et al. (eds.), EvoBIO Workshops 2004, LNCS 3005. Springer-Verlag, Berlin Heidelberg.

Vandecasteele, F.P.J (2006). Genetic algorithms to optimize functions of microbial ecosystems. PhD dissertation. University of Idaho

Van Nevel, L., Mertens, J., Oorts, K. \& Verheyen, K. (2007). Phytoextraction of metals from soils: How far from practice? Environ Pollut, 150:34-40.

Weathers, L.J., Parkin, G.F. \& Alvarez, P.J. (1997). Utilization of cathodic hydrogen as electron donor for chloroform cometabolism by a mixed, methanogenic culture. Environ. Sci.Technol. 31, 880-885

Weuster-Botz, D. \& Wandrey,C. (1995). Medium optimization by genetic algorithm for continuous production of formate dehydrogenase, Process. Biochem, 30: 563571.

Weuster-Botz, D., Pramatarova, V., Spassov,G., \& Wandrey, C. (1995). Use of a genetic algorithm in the development of a synthetic growth medium for Arthrobacter simplex with high hydrocortisone $\Delta 1$-dehydrogenase activity. J. Chem. Technol. Biotechnol, 64:386-392

Wolterink, A., Kim, S., Muusse, M., Kim, I.S., Roholl, P.J.M. \& van Ginkel,C.G. (2005). Dechloromonas hortensis sp. nov. and strain ASK-1, two novel (per)chloratereducing bacteria, and taxonomic description of strain GR-1. Int J Syst Evol Microbiol, 55: 2063-2068

Xu, J., Song, Y., Min, B., Steinberg, L. \& Logan, B.E. (2003). Microbial degradation of perchlorate: principles and applications. Environ Eng. Sci. 20, 405-422

Yifru, D.D. \& Nzengung, V. A. (2006). Uptake of Perchlorate by Vegetation Growing at Field Sites in Arid and Subhumid Climates. Remediation, Autumn 2007. p. 53-68.

Yu,L., Ca nas,J.E, Cobb,G.P., W.A. Jackson, W.A. \& Anderson, T.A. (2004). Uptake of perchlorate in terrestrial plants. Ecotoxicol. Envi-Qual, 29:866-870

Yu, X., Amrheim, C., Deshusses, M.A. \& Matsumoto, M.R. (2006). Perchlorate reduction by autotrophic bacteria in the presence of zero-valent iron. Environ. Sci. Technol. 40, 1328-1334 
Zafar, M., Kumar, S. \& Kumas, S. (2010). Optimization of napthalene biodegradation by a genetic algorithm based response surface methodology. Braz J Chem Engin, 27(01) 89-99 


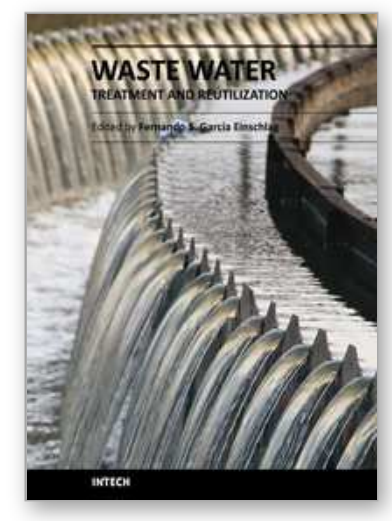

\author{
Waste Water - Treatment and Reutilization \\ Edited by Prof. Fernando Sebastiẽ $i n$ GarcÃa Einschlag
}

ISBN 978-953-307-249-4

Hard cover, 434 pages

Publisher InTech

Published online 01, April, 2011

Published in print edition April, 2011

The steady increase in industrialization, urbanization and enormous population growth are leading to production of huge quantities of wastewaters that may frequently cause environmental hazards. This makes waste water treatment and waste water reduction very important issues. The book offers a collection of studies and findings concerning waste water treatment, minimization and reuse.

\title{
How to reference
}

In order to correctly reference this scholarly work, feel free to copy and paste the following:

Katarzyna H. Kucharzyk, Terence Soule, Andrzej, J.Paszczynski and Thomas F. Hess (2011). Perchlorate: Status and Overview of New Remedial Technologies, Waste Water - Treatment and Reutilization, Prof. Fernando Sebastî̃ in GarcÃa Einschlag (Ed.), ISBN: 978-953-307-249-4, InTech, Available from: http://www.intechopen.com/books/waste-water-treatment-and-reutilization/perchlorate-status-and-overview-ofnew-remedial-technologies

\section{INTECH}

open science | open minds

\author{
InTech Europe \\ University Campus STeP Ri \\ Slavka Krautzeka 83/A \\ 51000 Rijeka, Croatia \\ Phone: +385 (51) 770447 \\ Fax: +385 (51) 686166 \\ www.intechopen.com
}

\author{
InTech China \\ Unit 405, Office Block, Hotel Equatorial Shanghai \\ No.65, Yan An Road (West), Shanghai, 200040, China \\ 中国上海市延安西路65号上海国际贵都大饭店办公楼 405 单元 \\ Phone: +86-21-62489820 \\ Fax: $+86-21-62489821$
}


(C) 2011 The Author(s). Licensee IntechOpen. This chapter is distributed under the terms of the Creative Commons Attribution-NonCommercialShareAlike-3.0 License, which permits use, distribution and reproduction for non-commercial purposes, provided the original is properly cited and derivative works building on this content are distributed under the same license. 